\title{
Photoelectrocatalysis and electrocatalysis on silicon electrodes decorated with cubane-like clusters
}

Hou, Yidong; Abrams, Billie L.; Vesborg, Peter Christian Kjærgaard; Björketun, Mårten; Herbst, Konrad; Bech, Lone; Seger, Brian; Pedersen, Thomas; Hansen, Ole; Rossmeisl, Jan

Total number of authors:

13

Published in:

Journal of Photonics for Energy

Link to article, DOI:

10.1117/1.JPE.2.026001

Publication date:

2012

Document Version

Publisher's PDF, also known as Version of record

Link back to DTU Orbit

Citation (APA):

Hou, Y., Abrams, B. L., Vesborg, P. C. K., Björketun, M., Herbst, K., Bech, L., Seger, B., Pedersen, T., Hansen, O., Rossmeisl, J., Dahl, S., Nørskov, J. K., \& Chorkendorff, I. (2012). Photoelectrocatalysis and electrocatalysis on silicon electrodes decorated with cubane-like clusters. Journal of Photonics for Energy, 2.

https://doi.org/10.1117/1.JPE.2.026001

\section{General rights}

Copyright and moral rights for the publications made accessible in the public portal are retained by the authors and/or other copyright owners and it is a condition of accessing publications that users recognise and abide by the legal requirements associated with these rights.

- Users may download and print one copy of any publication from the public portal for the purpose of private study or research.

- You may not further distribute the material or use it for any profit-making activity or commercial gain

- You may freely distribute the URL identifying the publication in the public portal 


\section{Photonics for Energy}

\section{Photoelectrocatalysis and electrocatalysis on silicon electrodes decorated with cubane-like clusters}

Yidong Hou

Billie L. Abrams

Peter C.K. Vesborg

Mårten E. Björketun

Konrad Herbst

Lone Bech

Brian Seger

Thomas Pedersen

Ole Hansen

Jan Rossmeisl

Søren Dahl

Jens K. Nørskov

Ib Chorkendorff 


\title{
Photoelectrocatalysis and electrocatalysis on silicon electrodes decorated with cubane-like clusters
}

\author{
Yidong Hou, ${ }^{a}$ Billie L. Abrams, ${ }^{\mathrm{b}}$ Peter C.K. Vesborg, ${ }^{\mathrm{a}}$ \\ Mårten E. Björketun, ${ }^{c}$ Konrad Herbst, ${ }^{\text {b }}$ Lone Bech, ${ }^{\text {a }}$ Brian Seger, ${ }^{a}$ \\ Thomas Pedersen, ${ }^{d}$ Ole Hansen, ${ }^{d}$ Jan Rossmeisl, ${ }^{c}$ Søren Dahl, ${ }^{a}$ \\ Jens K. Nørskov, ${ }^{\text {,e,f }}$ and Ib Chorkendorff ${ }^{\mathrm{a}}$ \\ ${ }^{a}$ Technical University of Denmark, CINF, Department of Physics, DK-2800 Kongens Lyngby, \\ Denmark \\ ibchork@fysik.dtu.dk \\ ${ }^{b}$ Haldor Topsøe A/S, Nymøllevej 55, DK-2800 Kongens Lyngby, Denmark \\ ${ }^{\mathrm{c}}$ Technical University of Denmark, CAMD, Department of Physics, DK-2800 Kongens Lyngby, \\ Denmark \\ ${ }^{\mathrm{d}}$ Technical University of Denmark, Department of Micro- and Nanotechnology, DK-2800 \\ Kongens Lyngby, Denmark \\ ${ }^{\mathrm{e} S t a n f o r d ~ U n i v e r s i t y, ~ D e p a r t m e n t ~ o f ~ C h e m i c a l ~ E n g i n e e r i n g, ~ S t a n f o r d, ~ C a l i f o r n i a ~} 94305$ \\ ${ }^{\mathrm{f}}$ Center for Interface Science and Catalysis, SLAC National Accelerator Laboratory, \\ 2575 Sand Hill Road, Menlo Park, California 94025
}

\begin{abstract}
The influence of the cluster-core unit in cluster-decorated $p$-Si on photoelectrochemical (PEC) hydrogen evolution has been investigated using a homologous series of cubane-like heterobimetallic sulfide compounds. These compounds stem from the generic cluster structure $A_{3} \mathrm{~S}_{4}$ or $A_{3} B S_{4}(A=\mathrm{W}, \mathrm{Mo} ; B=\mathrm{Co}, \mathrm{Cu})$. We find that the Mo-based $(A=\mathrm{Mo})$ cluster-decorated Si photoelectrodes show higher PEC performance than otherwise equivalent $\mathrm{W}$-based $(A=\mathrm{W})$ cluster-decorated ones. This is consistent with higher electrocatalytic activity of the Mo-based clusters supported on $n$-Si when measured in the dark. The result of stability tests is that photoelectrodes decorated with clusters without $\mathrm{Co}(B \neq \mathrm{Co})$ can exhibit promising stability, whereas clusters of the structure $\mathrm{A}_{3} \mathrm{CoS}_{4}(A=\mathrm{W}, \mathrm{Mo})$ yield photoelectrodes that are highly unstable upon illumination. X-ray photoelectron spectroscopy (XPS) results suggest that both oxidation and material loss play a role in deactivation of the $\mathrm{A}_{3} \mathrm{CoS}_{4}$ materials. Additionally, we observe that the photocurrent depends linearly on the light intensity in the limiting current region, and the corresponding incident photon to current efficiency (IPCE) may reach approximately $80 \%$. Density functional theory (DFT) calculations of the clusters adsorbed on the hydrogen-terminated Si surface are used to estimate and compare cluster adsorption energies on the surface as well as the H-binding energies, which is a descriptor for electrocatalytic activity. () 2012 Society of Photo-Optical Instrumentation Engineers (SPIE). [DOI: 10.1117/1.JPE.2.026001]
\end{abstract}

Keywords: cubane-like cluster; silicon; photocathode; hydrogen evolution; density functional theory; photoelectrochemical.

Paper 11240P received Oct. 11, 2011; revised manuscript received Dec. 23, 2011; accepted for publication Jan. 31, 2012; published online Mar. 19, 2012.

\section{Introduction}

\subsection{Si Photocathodes for Solar Hydrogen}

Solar fuel production is a necessary step in the development of sustainable energy systems to meet global energy demand in the long term. In this context, many studies have focused on direct

0091-3286/2012/\$25.00 (C) 2012 SPIE 
solar-to-storable chemical energy in the form of chemical fuels such as hydrogen from water splitting and hydrocarbon compounds from $\mathrm{CO}_{2}$ reduction. ${ }^{1}$ Photoelectrochemical (PEC) water splitting into hydrogen and oxygen at semiconductor/electrolyte interfaces is one very attractive approach for obtaining clean hydrogen. One of the most critical issues in the solar water splitting system is to develop cost-effective photoelectrodes containing no noble metals, but with high efficiency and long-term stability in an aqueous environment.

Unfortunately, no appropriate material for a single-photon system for water splitting has yet been discovered. By combining a small band gap with a moderate band gap semiconductor, the two-photon tandem approach allows access to a larger part of the solar spectrum than singlephoton water splitting. For this reason, a two-photon tandem system may potentially achieve a higher solar-to-hydrogen efficiency. ${ }^{2-4}$ Although it introduces some complexity into the total system, the tandem approach also increases the degree of freedom for the choice of materials for the photoelectrodes. This is particularly important for positioning of the detailed bandstructure for the semiconductor, but also for selecting materials that are either resistive toward photocorrosion or materials that potentially can be protected by, for example, the oxygen or hydrogen envolving catalyst toward corrosion. ${ }^{5}$

When considering photocathode materials, silicon $(\mathrm{Si})$ is an interesting candidate as a light absorber due to the low band gap $(1.1 \mathrm{eV})$, which is close to the theoretical optimal band gap for the small band gap semiconductor in the tandem system for water splitting. This band gap enables effective utilization of the visible and infrared (IR) light from the sun. Additionally, Si is very abundant and thus potentially inexpensive. However, highly purified Si required for good electron-hole conduction might, to some extent, negate the cost advantage. Unfortunately, $\mathrm{Si}$ alone has very poor hydrogen evolution kinetics. It is thus necessary to catalyze the hydrogen evolution by functionalizing the Si surface with an electro-catalyst. ${ }^{6}$

\subsection{Hydrogen Evolution Reaction Catalysts for Si}

The activity of photoelectrodes is known to be strongly influenced by the choice of electrocatalyst. For hydrogen evolution reaction (HER) on $p$-Si photocathodes, it is well known that $\mathrm{Pt}$ is the most efficient co-catalyst amongst the metals-particularly in acidic media. ${ }^{7}$ The variation in activity between the different metals can be attributed to the different Gibbs energy associated with the formation and cleavage of the metal-hydrogen bond at the active site. ${ }^{8}$ Platinum and other noble metals, however, are too scarce to be used for large-scale hydrogen production despite their attractive activity, and therefore abundant alternatives are needed. Using the free energy of hydrogen adsorption, $\Delta \mathrm{G}_{\mathrm{H}}$, as a descriptor for identifying HER catalysts $^{8}$ and inspired by the active site in the enzyme nitrogenase, we have previously found that $\mathrm{MoS}_{2}$ nanoparticles are good catalysts for this reaction. ${ }^{9}$ Extending this line of research, we found that $\mathrm{WS}_{2}$ has a HER activity similar to that of $\mathrm{MoS}_{2}$ and that transition metals such as cobalt promoted both materials for hydrogen evolution. ${ }^{10}$ More recently, the bio-mimetic approach has been extended to include cubane-type molecular metal-sulfide clusters, ${ }^{11}$ and in a recent study we demonstrated that $p$-Si photocathodes can be modified with an incomplete cubane-like $\mathrm{Mo}_{3} \mathrm{~S}_{4}$ cluster and efficiently activated toward HER upon illumination. ${ }^{12}$ Cubane clusters are interesting as a class of molecular catalysts-especially due to the numerous heterobimetallic derivatives of the incomplete cubane-like cluster cores $A_{3} \mathrm{~S}_{4}(A=\mathrm{Mo}, W)$ that have become preparatively available during the last two decades. ${ }^{13,14}$ The "complete" cubane-like cluster cores $\left(A_{3} B \mathrm{~S}_{4}\right)$ are prepared by heterometal insertion in the incomplete cluster cores, ${ }^{15-20}$ but the application of these complete cubane clusters as electro-catalysts remains largely unexplored.

This study explores the properties of diverse cubane clusters in the materials parameter space. The aim is to gain knowledge in facilitating the design of the new catalysts with improved HER. Here, we investigate in detail the effect of the cluster-core unit on PEC hydrogen evolution using the homologous series of cubane-like clusters of $A_{3} \mathrm{~S}_{4}$ and $A_{3} B \mathrm{~S}_{4}(A=\mathrm{W}$, $\mathrm{Mo} ; B=\mathrm{Co}, \mathrm{Cu}$ ) on $p$-Si. Density functional theory (DFT) calculations of the clusters adsorbed on the hydrogen-terminated Si surface are performed in order to simulate adsorption 
phenomena in these systems. In particular, the importance of $\mathrm{H}$ absorption and $\mathrm{OH}$ absorption are addressed by DFT. $^{21}$

\section{Experimental Section}

\subsection{Cluster Synthesis}

The monometallic cluster compounds $\left[\left(\eta^{5}-\mathrm{Cp}^{\prime}\right)_{3} A_{3} \mathrm{~S}_{4}\right][\mathrm{pts}](A=\mathrm{Mo}, \mathrm{W}$; pts $=p$-toluenesulfonate) were prepared by substituting the aqua ligands in $\left[\left(\mathrm{H}_{2} \mathrm{O}\right)_{9} A_{3} \mathrm{~S}_{4}\right][\mathrm{pts}]_{4} \cdot 9 \mathrm{H}_{2} \mathrm{O}$ for methylcyclopentadienyl $\left(\mathrm{Cp}^{\prime}\right)$ ligands, followed by chromatographic purification on silica gel and crystallization. For the preparation of the bimetallic clusters $\left[\left(\eta^{5}-\mathrm{Cp}^{\prime}\right){ }_{3} A_{3} \mathrm{~S}_{4} \mathrm{Cu}(\mathrm{Cl})\right][\mathrm{pts}]$ and $\left[\left(\eta^{5}-\mathrm{Cp}^{\prime}\right){ }_{3} A_{3} \mathrm{~S}_{4} \mathrm{Co}(\mathrm{CO})\right],\left[\left(\eta^{5}-\mathrm{Cp}^{\prime}\right){ }_{3} A_{3} \mathrm{~S}_{4}\right][\mathrm{pts}](A=\mathrm{Mo}, \mathrm{W})$ was reacted with $\mathrm{CuCl}$ and $\mathrm{Co}_{2}(\mathrm{CO})_{8}$, respectively. Details of the preparations were reported elsewhere. ${ }^{15-20}$ When used in general terms, the compounds are abbreviated as $A_{3} \mathrm{~S}_{4}$ and $A_{3} B \mathrm{~S}_{4},(A=\mathrm{W}, \mathrm{Mo}, B=\mathrm{Co}$, $\mathrm{Cu})$ clusters throughout the manuscript. Drawings of the clusters are shown in Fig. 1.

\subsection{Electrode Preparation}

Single crystal B-doped ( $p$-type, (100) oriented, $0.5 \mathrm{~mm}$ thick, $2.2 \Omega \mathrm{cm}$ resistivity) and P-doped (n-type, (100) oriented, $0.5 \mathrm{~mm}$ thick, 1 to $20 \Omega \cdot \mathrm{cm}$ resistivity) wafers provided by Okmetic were employed for making all electrodes. We have found that the evolving hydrogen bubbles adhere to the electrode surface during activity test, resulting in a nonreproducible loss of effective active area. To avoid this problem and to lower optical reflection losses, the silicon surface was textured with a pyramid structure in this study. Pyramid surface texture was formed by dipping the wafers in a mixture of $2.5 \mathrm{wt} \% \mathrm{KOH}$ with $5 \mathrm{vol} \%$ isopropanol aqueous solution at $70^{\circ} \mathrm{C}$ for $60 \mathrm{~min}$. The pyramid-shaped pits thus etched in the surface are (111) terminated. ${ }^{22}$ After etching, the silicon
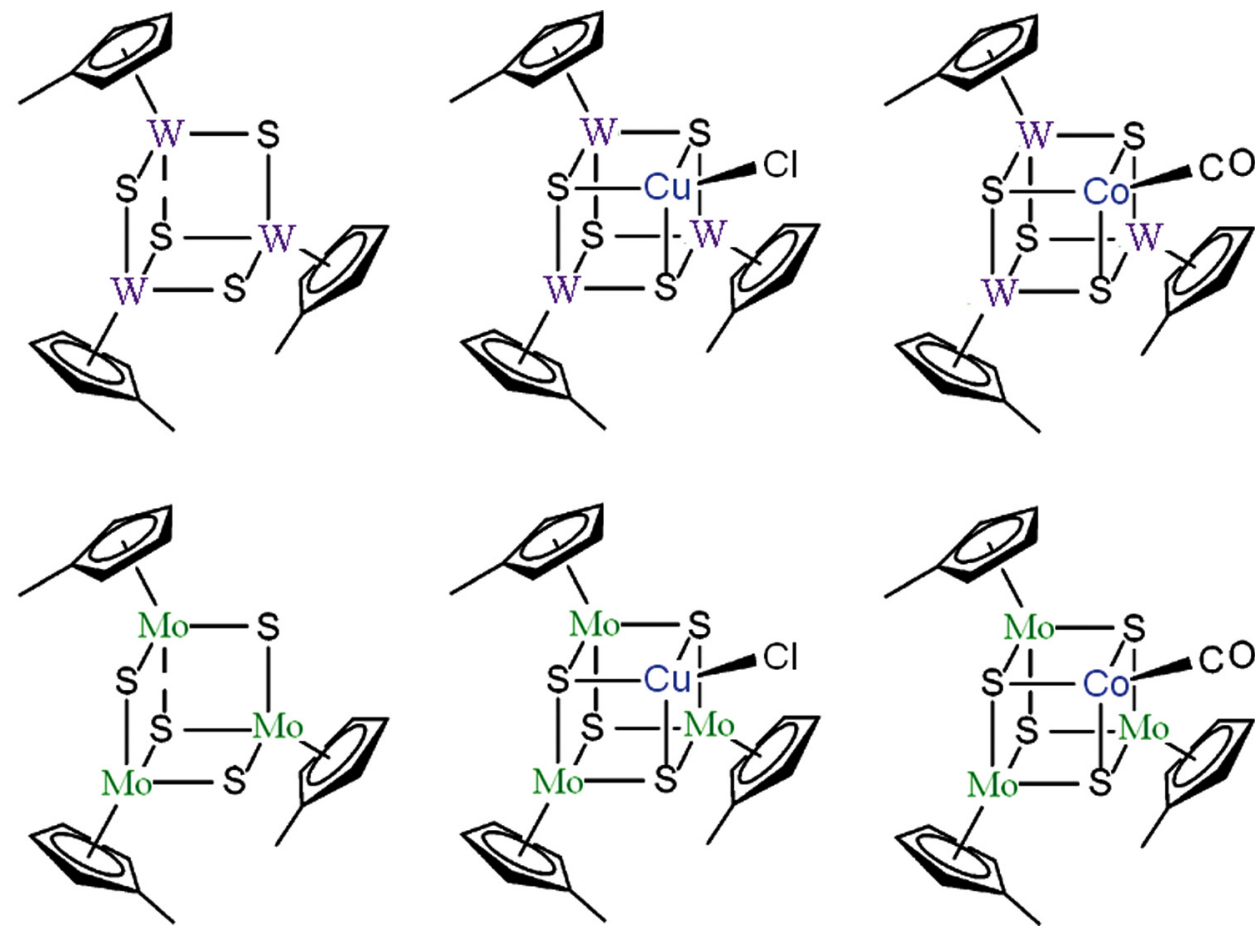

Fig. 1 Drawing of the $A_{3} \mathrm{~S}_{4}$ and $A_{3} B S_{4},(A=\mathrm{W}, \mathrm{Mo}, B=\mathrm{Co}, \mathrm{Cu})$ clusters. The $A_{3} \mathrm{~S}_{4}$ and $A_{3} \mathrm{CuS}_{4}$ clusters are cationic, with $p$-toluenesulfonate (pts) as anion, which is not shown here. The $A_{3} \operatorname{CoS}_{4}$ clusters are electroneutral. 
wafers were rinsed with ultrapure water $(>18.2 \mathrm{M} \Omega \mathrm{cm}$ ), dried by blowing nitrogen, and cut into smaller $16 \times 20-\mathrm{mm}^{2}$ Si chips.

Ohmic contacts were made using a eutectic gallium-indium alloy. The electrode was wrapped with polytetrafluoroethylene (PTFE)tape, exposing an area of $0.25 \mathrm{~cm}^{2}$ on the front side of the $\mathrm{Si}$ electrode. Just before use or cluster deposition, the Si electrode was immersed in 1\% hydrofluoric acid (HF) aqueous solution for $1 \mathrm{~min}$ at room temperature to strip off the native silicon oxide on the surface. The H-terminated Si electrode thus obtained was either rinsed with ultrapure water and transferred into the photoelectrochemical cell for testing or further treated with the clusters before testing.

Cluster-modified Si electrodes were prepared by the following drop-casting method: $20 \mu \mathrm{L}$ of the cluster solution was drop-cast onto a freshly prepared H-terminated Si electrode (total loading: $2 \mathrm{nmol}$ of clusters). After dropping the cluster solution onto the silicon, the electrode was heated to $60^{\circ} \mathrm{C}$ to flash off the solvent $\left(\mathrm{CH}_{2} \mathrm{Cl}_{2}: \mathrm{CH}_{3} \mathrm{OH}\right)$. Immediately after deposition, the sample was transferred to the photoelectrochemical cell.

\subsection{Characterization}

The microstructure and morphology of the samples were investigated by a JSM-6700F scanning electron microscope (SEM). UV-vis diffuse reflectance spectroscopy was measured with a calibrated spectroradiometer equipped with an integrating sphere and a commercial $100 \%$ reflectance standard. X-ray photoelectron spectroscopy (XPS) was used to analyze the surface chemistry and chemical state of the cubane cluster supported on silicon used in this work. XPS was performed using a Theta-Probe UHV setup from Thermo-Fischer with monochromatized $\mathrm{AlK}_{\alpha}$ radiation. The energy resolution used corresponded to $\mathrm{Ag} 3 \mathrm{~d}_{5 / 2}$ full-width half-maximum of better than $1.0 \mathrm{eV}$. The XPS binding energies were referenced against $\mathrm{C} 1 \mathrm{~s}$ at $285.0 \mathrm{eV}$.

\subsection{Photocatalytic Measurements}

The light source used was a 1000-W Xe lamp (Newport 66924) with a water filter for filtering out the long wavelength part of the radiation. The light was further filtered by an "AM1.5G filter" (Newport 81094) to approximate the solar spectrum and further with a 635-nm long-pass filter (Newport FSR-RG645) to discard the blue and green photons $(h \nu>2 \mathrm{eV})$. The overall light intensity was controlled using neutral density filters to either approximate the solar level for most of the measurements reported in the paper or, in special cases, to obtain higher intensities. The irradiance spectrum of the light incident at the electrode surface was measured with the spectroradiometer. Photocurrents of the Si electrodes (working electrode, WE) were measured in a gas-tight, three-electrode cell made from Pyrex glass with an aqueous $1 \mathrm{M} \mathrm{HClO}_{4}$ solution as electrolyte. A commercial $\mathrm{Hg} / \mathrm{HgSO}_{4}$ electrode was used as the reference electrode (RE) and a platinum mesh as counter electrode (CE). The $\mathrm{CE}$ was separated from the working electrode (WE) and RE by a glass frit. The potential of the commercial $\mathrm{Hg} / \mathrm{HgSO}_{4}$ electrode was calibrated against an in situ reversible hydrogen electrode (RHE) before the experiment. The potential of the WE was controlled by a potentiostat (Biologic VSP) and was recalculated against RHE, but no corrections for ohmic drops were made. The electrolyte was de-aerated by bubbling with hydrogen before and during measurements. Great care was taken to avoid the contamination of the WE (and WE compartment of the cell) with Pt from the CE. As a case in point, the CE compartment was bubbled with hydrogen such that the $\mathrm{CE}$ remained close to $0 \mathrm{~V}$ RHE even when drawing a current. This served to minimize dissolution of Pt into the $\mathrm{CE}$ compartment.

\subsection{DFT Calculations}

The DFT calculations were carried out within the plane-wave $e^{23,24}$ pseudopotential approach, as implemented in the DACAPO total energy code. ${ }^{25}$ The Revised Perdew-Burke-Ernzerhof (RPBE) version of the exchange-correlation functional ${ }^{26}$ was employed in all calculations and the ion cores were represented by ultrasoft pseudopotentials. ${ }^{27}$ In gas-phase calculations of $A_{3} \mathrm{~S}_{4}$ and $A_{3} B \mathrm{~S}_{4}(A=\mathrm{W}, \mathrm{Mo} ; B=\mathrm{Co}, \mathrm{Cu})$ incomplete and complete cubane clusters, 
periodically repeated $15 \times 15 \times 15 \AA$ supercells were used. These cells should be large enough to remove spurious interactions between neighboring molecules. $\mathrm{Si}(100)$ and $\mathrm{Si}(111)$ surfaces were modeled using periodically repeated slabs, $3 \times 3$ surface unit cells wide and six layers thick, separated by at least $14.8 \AA$ vacuum in the z-direction. Adsorbed cubane clusters and hydrogen were placed on one side of the slab. This setup creates an asymmetric slab with a nonvanishing surface-dipole density. Hence, the dipole correction ${ }^{28}$ was introduced to correct the electrostatic potential in the vacuum region. A $340 \mathrm{eV}$ cutoff was used for the expansion of the one-electron wave functions, and a $500 \mathrm{eV}$ cutoff was used for the charge density. For the Brillouin zone sampling a $4 \times 4 \times 1$ Monkhorst-Pack k-point mesh was employed. Spin-polarization effects were included in calculations on systems containing the naturally magnetized element $\mathrm{Co}$. The three bottom layers of the Si slab were kept fixed in their RPBE bulk positions during structural optimization of the various systems, while the three upper layers of the slab and adsorbates were free to move until all forces were less than $0.01 \mathrm{eV} / \AA$.

\section{Results and Discussion}

\subsection{Silicon Surface Morphology}

Typical SEM images of the obtained silicon wafers after etching in $2.5 \% \mathrm{KOH}$ solution are shown in Fig. 2. The pyramid structures are formed from planar $p$-type silicon as well
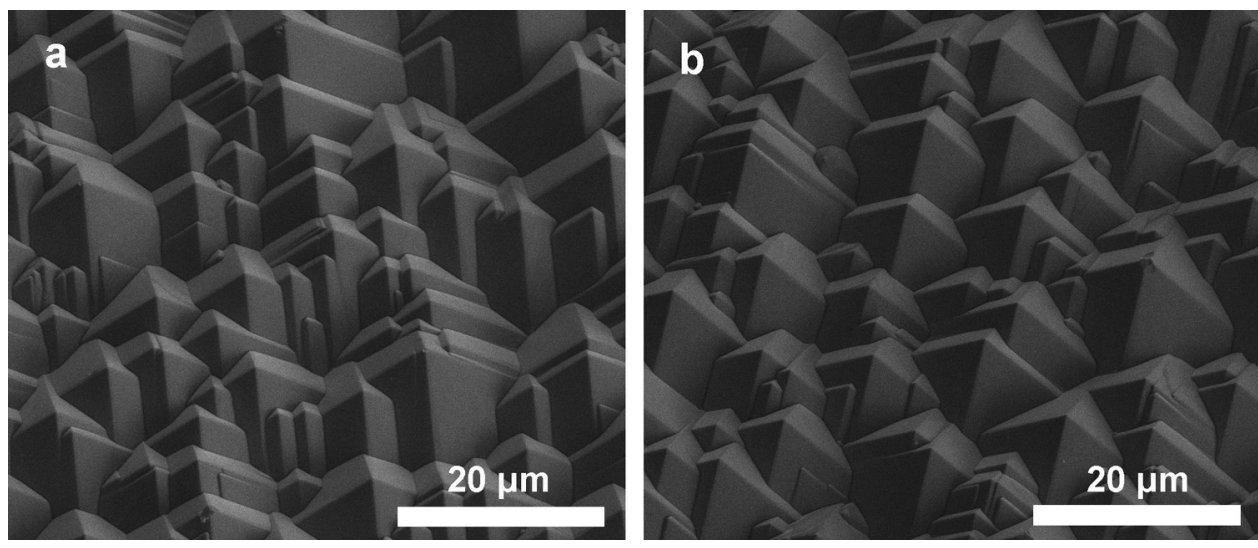

Fig. 2 SEM images of the typical pyramid-like structure of the silicon surface for (a) $p$-Si and (b) $n$-Si.

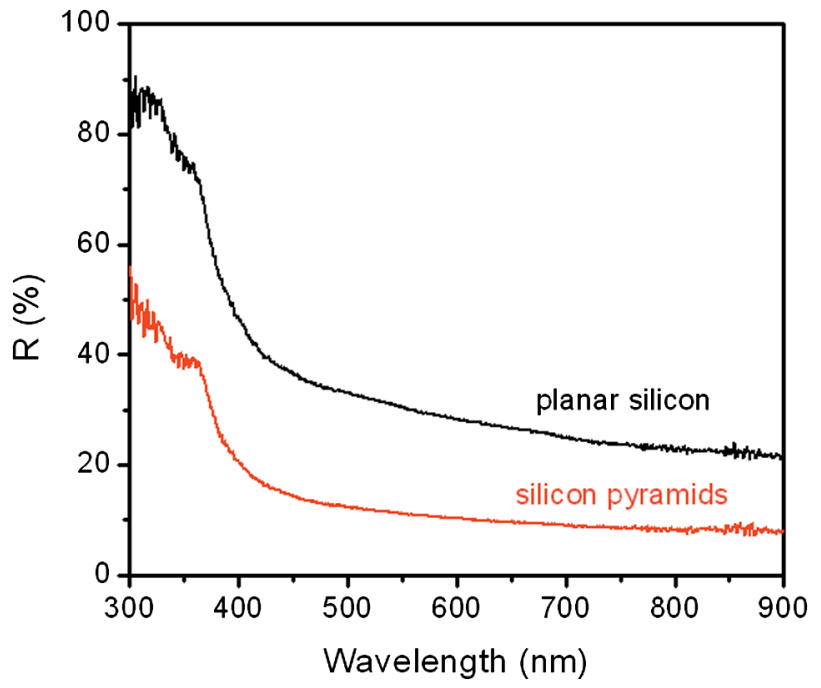

Fig. 3 Measured reflectance spectra of $p$-type planar silicon and silicon pyramids. 
as $n$-type silicon. The height of the pyramids ranges from 2 to $6 \mu \mathrm{m}$. As expected, pyramidstructured surfaces decrease light reflection, which can be seen in the UV-vis spectra of the silicon pyramids and planar silicon shown in Fig. 3. The overall reflectance of a pyramidstructured silicon surface at normal incidence is less than $10 \%$ in the range of 600 to $900 \mathrm{~nm}$, while the reflectance of planar silicon at normal incidence is about $25 \%$. Lower reflectance as well as the higher surface area of the silicon pyramids will contribute to higher absorption and photocurrent of the electrodes. In this study, we only report the results on pyramid-structured silicon substrates.

\subsection{Dependence of the Photocurrent on Cluster Structure}

Figure 4 shows a comparison of the photocurrent-voltage curves associated with clusterdecorated and bare $p$-Si photoelectrodes. All the electrodes show negligible current in the dark (not shown). Upon illumination, however, the clusters significantly improve the performance for the PEC generation of hydrogen compared to bare $p$-Si. The bare $p$-Si shows a current density of $8 \mathrm{~mA} / \mathrm{cm}^{2}$ at the potential of $-0.6 \mathrm{~V}$ vs. RHE. As seen in both Figs. 4(a) and 4(b), there is a large positive shift in potential once the $p$-Si is decorated with cubane-like clusters. At a current density of $8 \mathrm{~mA} / \mathrm{cm}^{2}$, this potential shift is measured to be about 0.3 to $0.35 \mathrm{~V}$ for W-based clusters and up to $0.6 \mathrm{~V}$ for Mo-based clusters. During the cycled current-voltage scans, the activity of $\mathrm{Co}_{3} \mathrm{~S}_{4}(A=\mathrm{W}, \mathrm{Mo})$ cluster-decorated electrodes deteriorates. In other cases (i.e., for clusters without $\mathrm{Co}$ ), the electrodes remain quite stable and identical results are observed in the cycled runs.
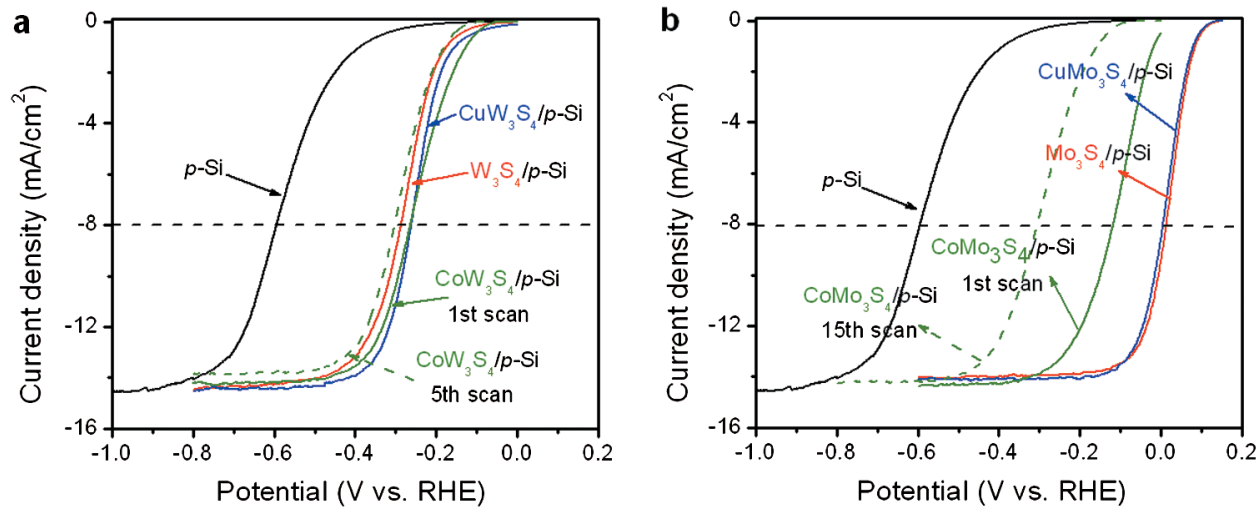

Fig. 4 The potentiodynamic scans of the $p$-Si photoelectrodes decorated with (a) W-based clusters and (b) Mo-based clusters, with the bare $p$-Si (black curves) as a control in both cases.

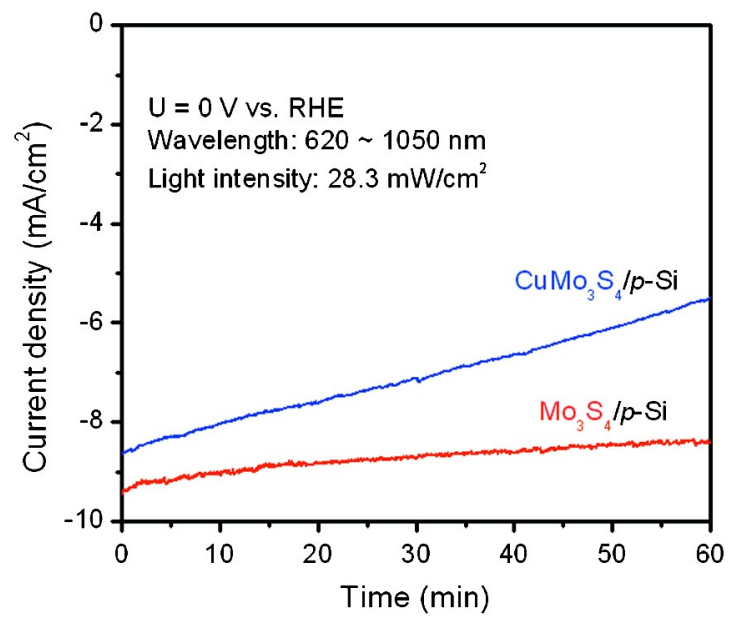

Fig. 5 Dependence of current-density on time over $\mathrm{Mo}_{3} \mathrm{~S}_{4} / p$-Si and $\mathrm{CuMo}_{3} \mathrm{~S}_{4} / p$-Si electrodes. 
Table 1 Comparison of the dark electrocatalytic activity of the clusters supported on $n$-Si in terms of the overpotential and Tafel slope. Also indicated are cubane adsorption energies as well as hydrogen, oxygen, and hydroxyl adsorption free energies obtained from DFT calculations. The adsorption free energies have been calculated assuming equilibrium with liquid water and 1 bar $\mathrm{H}_{2}$ gas at $300 \mathrm{~K}$.

\begin{tabular}{lcccccc} 
Cluster & $\begin{array}{c}\eta \mathrm{mA} \\
\mathrm{mA} / \mathrm{cm}^{2} \\
(\mathrm{~V})\end{array}$ & $\begin{array}{c}\text { Tafel slope } \\
(\mathrm{mV} / \text { decade })\end{array}$ & $\begin{array}{c}E_{\mathrm{ads}}(\mathrm{eV}) \\
(100) /(111)\end{array}$ & $\begin{array}{c}\Delta G_{H *}(\mathrm{eV}) \\
(100) /(111)\end{array}$ & $\begin{array}{l}\Delta G_{O_{*}}(\mathrm{eV}) \\
(100) /(111)\end{array}$ & $\begin{array}{c}\Delta G_{\mathrm{OH}_{*}(\mathrm{eV})} \\
(100) /(111)\end{array}$ \\
\hline $\mathrm{W}_{3} \mathrm{~S}_{4}$ & -0.81 & 97 & $-2.7 / 0.4$ & $0.82 / 0.20$ & $1.34 / 1.20$ & $1.13 / 0.23$ \\
$\mathrm{CuW}_{3} \mathrm{~S}_{4}$ & -0.82 & 136 & $-/-$ & $-/-$ & $-/-$ & $-/-$ \\
$\mathrm{CoW}_{3} \mathrm{~S}_{4}$ & -0.81 & 124 & $-/-$ & $-/-$ & $-/-$ & $-/-$ \\
$\mathrm{Mo}_{3} \mathrm{~S}_{4}$ & -0.55 & 55 & $-4.5 /-1.6$ & $0.44 / 0.26$ & $0.47 /-0.43$ & $0.34 /-1.03$ \\
$\mathrm{Mo}_{3} \mathrm{~S}_{4} \mathrm{O}$ & - & - & $-/-$ & $-/ 0.27$ & $-/-$ & $-/-$ \\
$\mathrm{Mo}_{3} \mathrm{~S}_{4} \mathrm{OH}$ & - & - & $-/-$ & $-/ 0.29$ & $-/-$ & $-/-$ \\
$\mathrm{CuMo}_{3} \mathrm{~S}_{4}$ & -0.53 & 50 & $-4.2 /-1.4$ & $-0.26 /-0.42$ & $0.14 /-0.75$ & $-0.24 /-0.93$ \\
$\mathrm{CuMo}_{3} \mathrm{~S}_{4} \mathrm{O}$ & - & - & $-/-$ & $0.24 / 0.38$ & $-/-$ & $-/-$ \\
$\mathrm{CuMo}_{3} \mathrm{~S}_{4} \mathrm{OH}$ & - & - & $-/-$ & $0.16 / 0.34$ & $-/-$ & $-/-$ \\
$\mathrm{CoMo}_{3} \mathrm{~S}_{4}$ & -0.55 & 57 & $-0.8 /-0.2$ & $-1.07 /-1.07$ & $-1.39 /-0.25$ & $-1.47 /-1.03$ \\
$\mathrm{CoMo}_{3} \mathrm{~S}_{4} \mathrm{O}$ & - & - & $-/-$ & $0.38 / 0.20$ & $-/-$ & $-/-$ \\
$\mathrm{CoMo}_{3} \mathrm{~S}_{4} \mathrm{OH}$ & - & - & $-/-$ & $0.46 / 0.16$ & $-/-$ & $-/-$ \\
\hline \hline
\end{tabular}

\subsection{Stability of Electrodes}

The stability of both $\mathrm{Mo}_{3} \mathrm{~S}_{4}$ and $\mathrm{CuMo}_{3} \mathrm{~S}_{4}$ systems on $p$-Si can be seen in Fig. 5. Under continuous illumination at the reversible potential for hydrogen evolution, the hydrogen bubbles from the electrode surface are easily observed. Over a $60 \mathrm{~min}$ period, the calculated number of electrons passing through the outer circuit is $81 \mu \mathrm{mol}$ for the $\mathrm{Mo}_{3} \mathrm{~S}_{4}$ system and $66 \mu \mathrm{mol}$ for the $\mathrm{CuMo}_{3} \mathrm{~S}_{4}$ system. This far exceeds the amount of the clusters ( $\left.2 \mathrm{nmol}\right)$ deposited onto the electrodes, indicating that the photocurrents result from photocatalytic hydrogen evolution and not from decomposition of the clusters. The photocurrent of $\mathrm{Mo}_{3} \mathrm{~S}_{4} / p-\mathrm{Si}$ drops a bit initially but seems to stabilize over time, whereas the photocurrent of $\mathrm{CuMo}_{3} \mathrm{~S}_{4} / p$-Si seems to drop consistently and deactivate over time. $\mathrm{Mo}_{3} \mathrm{~S}_{4} / p$-Si shows better durability compared to the complete cubane cluster $\mathrm{CuMo}_{3} \mathrm{~S}_{4} / p$-Si. This could be related to stronger adsorption of the cluster onto the silicon surface (binding energy on $\mathrm{Si}(111)$ of $-1.6 \mathrm{eV}$ vs. $-1.4 \mathrm{eV}$, shown in Table 1). The slow decrease in photocurrent could be a result of the evolved hydrogen diffusing below the clusters, causing a weakening of the interaction between cluster and silicon surface, but it could also simply be due to residual oxygen in the system.

\subsection{Dependence of Photocurrent and Incident Photon to Current Efficiency (IPCE) on Light Intensity}

Figure 6(a) shows the current-potential curves over the $\mathrm{Mo}_{3} \mathrm{~S}_{4} / p$-Si electrode (best system) at varying levels of irradiance (no IR compensation despite current density up to $80 \mathrm{~mA} / \mathrm{cm}^{2}$ ). The photocurrent increases with the increase of the irradiance intensity. The IPCE is the ratio of photocurrent, $I$, to incident photon flux $\left(J=\int_{620}^{1050} N(\lambda) \mathrm{d} \lambda\left[\mathrm{s}^{-1} \mathrm{~cm}^{-2}\right]\right)$ at a given irradiance. We use the external photon flux (hitting the window of the cell) for the calculation of $J$. The curve at $28.3 \mathrm{~mW} / \mathrm{cm}^{2}$ corresponds to the red part $(\lambda>620 \mathrm{~nm})$ of $1 \times$ AMI.5G. Figure $6(\mathrm{~b})$ 
Hou et al.: Photoelectrocatalysis and electrocatalysis on silicon electrodes...
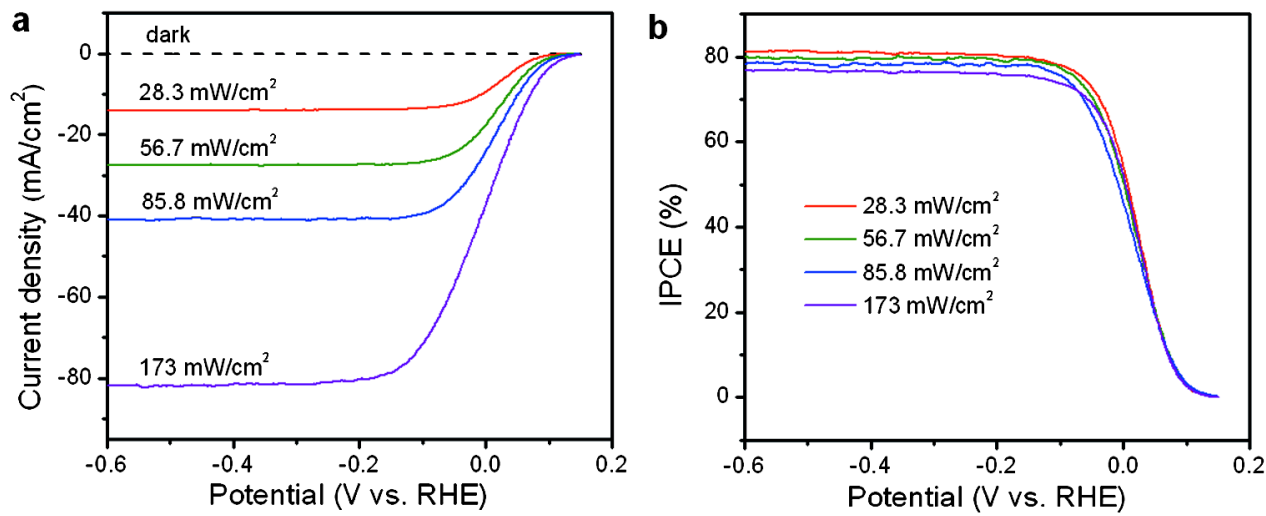

Fig. 6 Dependence of (a) current-density and (b) the calculated incident photon-to-current conversion (IPCE) as a function of light intensity over the $\mathrm{Mo}_{3} \mathrm{~S}_{4} / p$-Si electrode.

shows that the limiting photocurrent at steady state (the plateau at negative potential) is approximately linearly dependent on the light intensity up to a power density of (at least) $28.3 \mathrm{~mW} / \mathrm{cm}^{2}$ (i.e., $I \propto J)$. The constant and high IPCE ( $~ 80 \%$ at the plateau) means that the photocathode handles light concentration well. This is similar to what has been reported over silicon pillars. ${ }^{12}$

\subsection{XPS of $\mathrm{COMo}_{3} \mathrm{~S}_{4} / p-\mathrm{Si}$}

During cyclic scans of the Mo-based cluster-decorated $p$-Si photoelectrodes under illumination, the PEC performance of the $\mathrm{CuMo}_{3} \mathrm{~S}_{4} / p$-Si electrode deteriorated notably. XPS was used to characterize the $\mathrm{CuMo}_{3} \mathrm{~S}_{4}$ decorated $p$-Si photoelectrodes after the 1 st cycle and the 15 th
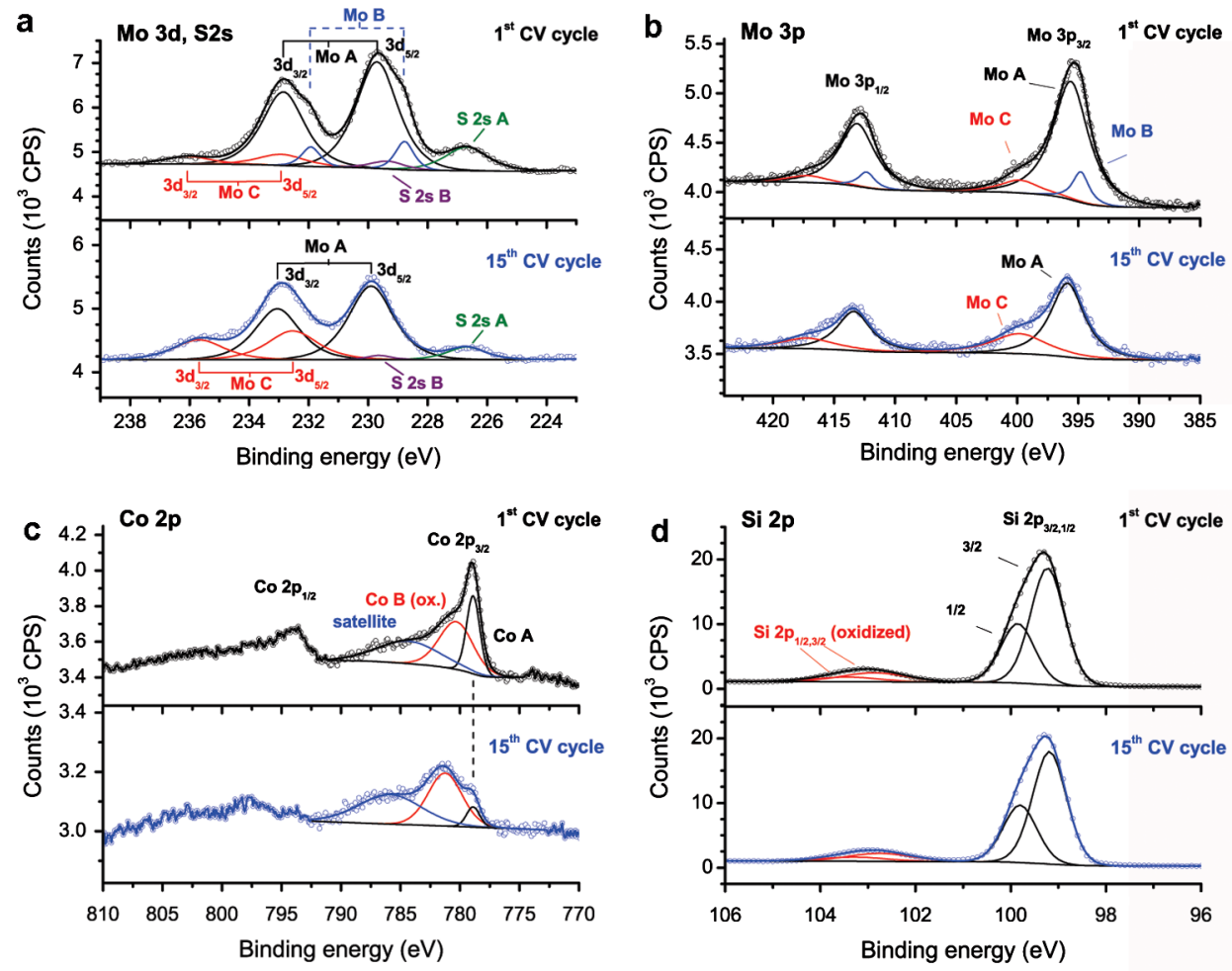

Fig. 7 XPS spectra recorded at $\mathrm{CuMo}_{3} \mathrm{~S}_{4} / p$-Si photoelectrodes after 1 st cycle and 15th cycle. (a) Mo 3d and S 2s; (b) Mo 3p; (c) Co 2p; and (d) Si 2p. The experimental spectra are depicted with open circles. Solid curves show the deconvolution obtained by fitting. 
Hou et al.: Photoelectrocatalysis and electrocatalysis on silicon electrodes...

cycle, as can be seen in Fig. 7. The observed changes were quantified by deconvolution of the Mo 3d, S 2s, Mo 3p, and Si 2p features using constraints and an iterative process, as reported elsewhere reported. ${ }^{12}$ The deconvolution process also ensured consistency with the XPS spectra of Si $2 \mathrm{~s}$ and $\mathrm{S} 2 \mathrm{p}$ (not shown), and was previously used for the analysis of $\mathrm{Mo}_{3} \mathrm{~S}_{4} / p$-Si. After the 1 st cycle, the spectrum with the overlapping Mo $3 \mathrm{~d}$ and $\mathrm{S} 2 \mathrm{~s}$ features is dominated by a Mo $3 \mathrm{~d}$ spin-orbit doublet with a clear shoulder on the low binding energy side. Decomposition into contributions from different chemical states gives a binding energy of $229.7 \mathrm{eV}$ for the dominant Mo $3 \mathrm{~d}_{5 / 2}$ component (Mo A) and a second component shifted $0.9 \mathrm{eV}$ towards lower binding energy (Mo B). This is very similar to our observations on $\mathrm{Mo}_{3} \mathrm{~S}_{4} / p$-Si. ${ }^{12}$ In line with that, Mo A is attributed to the $\mathrm{CuMo}_{3} \mathrm{~S}_{4}$ clusters, and the shoulder (Mo B) could originate from substrate interaction. The presence of oxidized Mo, represented by Mo C, is insignificant in the active phase. A S 2s feature (S 2s A) is clearly observed at $226.7 \mathrm{eV}$, equivalent within $0.1 \mathrm{eV}$ to the observations at $\mathrm{Mo}_{3} \mathrm{~S}_{4} / p$-Si, where the corresponding feature was attributed to sulfur atoms coordinated twofold to Mo atoms. ${ }^{12}$ For the $\mathrm{CoMo}_{3} \mathrm{~S}_{4}$ cluster, these sulfur atoms are further coordinated to Co. Good fits of the combined Mo 3d S 2s and the S 2p Si 2s spectra could be obtained when another $S$ feature (S 2s B) with a third of the intensity of the $S$ A feature was included, consistent with the $3: 1$ ratio of sulfur atoms coordinated twofold and threefold to Mo atoms in $\mathrm{CoMo}_{3} \mathrm{~S}_{4}$. After the 15th cycle, the oxidized state of Mo $\mathrm{C}$ became more dominant, whereas Mo A is reduced and Mo B disappeared, indicating oxidation and rearrangement of the former $\mathrm{CoMo}_{3} \mathrm{~S}_{4}$ cluster. There is, on the other hand, no indication of significant substrate changes in the XPS spectra, which show nearly unaltered $\mathrm{Si} 2 \mathrm{p}$ intensities and only a minor increase in the ratio of the $\mathrm{Si}$ that is oxidized (from $11 \%$ to $15 \%$ ). For Co $2 \mathrm{p}_{3 / 2}$, a feature dominates initially at a binding energy of $778.9 \mathrm{eV}$, which is attributed to the $\mathrm{Co}$ of the $\mathrm{CoMo}_{3} \mathrm{~S}_{4}$ structure. After the 15 th cycle, it is strongly reduced and a feature that peaks at higher binding energy dominates. At the same time, the broad satellite at higher binding energy gets more significant. These changes are consistent with oxidation (and partial loss) of Co. Further, according to the intensity changes corrected for relative sensitivity factors, the oxygen content on the surface grows at the expense cost of $\mathrm{Co}, \mathrm{Mo}$, and $\mathrm{S}$. The oxidation, structure change, and loss of $\mathrm{CoMo}_{3} \mathrm{~S}_{4}$ seem to be the reason for the deactivation of $\mathrm{CoMo}_{3} \mathrm{~S}_{4} / p$-Si photoelectrode during cyclic scanning.

\subsection{Dependence of the Electrocatalytic Activity on Cluster Structure}

In order to gain better insight into the catalytic effect of the clusters, we also investigated the behavior of cluster-decorated $n$-type $\mathrm{Si}$. Since the electron is the majority carrier for $n$-type semiconductors, the proton reduction process can run in the dark on $n$-Si, similar to a metallic electrode. As suggested previously for platinized surfaces, ${ }^{6}$ we assume that the surface chemistry of $n$-type and $p$-type $\mathrm{Si}$ will be the same with respect to the interaction between the clusters and the silicon surface. This is a key point when examining the behavior of cluster-decorated $n$-Si in the dark, allowing better understanding of the behavior of clusters supported on $p$-type silicon. $n$-Si electrodes were deposited with the same amount of clusters as used for the $p$-Si photocathodes.
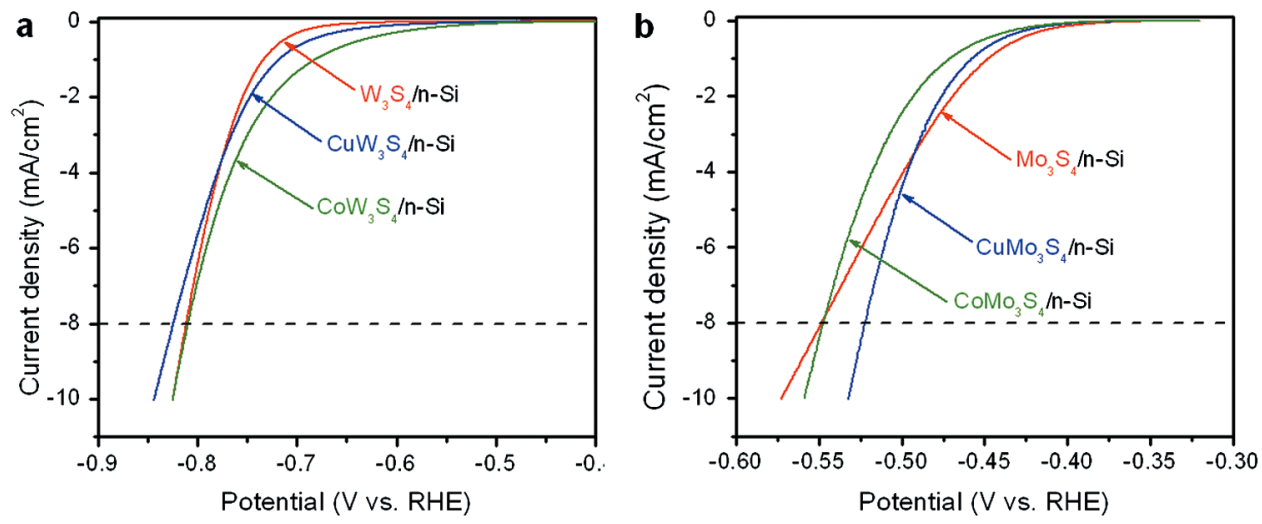

Fig. 8 Current density-voltage curves (HER) for the $n$-Si electrodes decorated with (a) W-based clusters and (b) Mo-based clusters. 

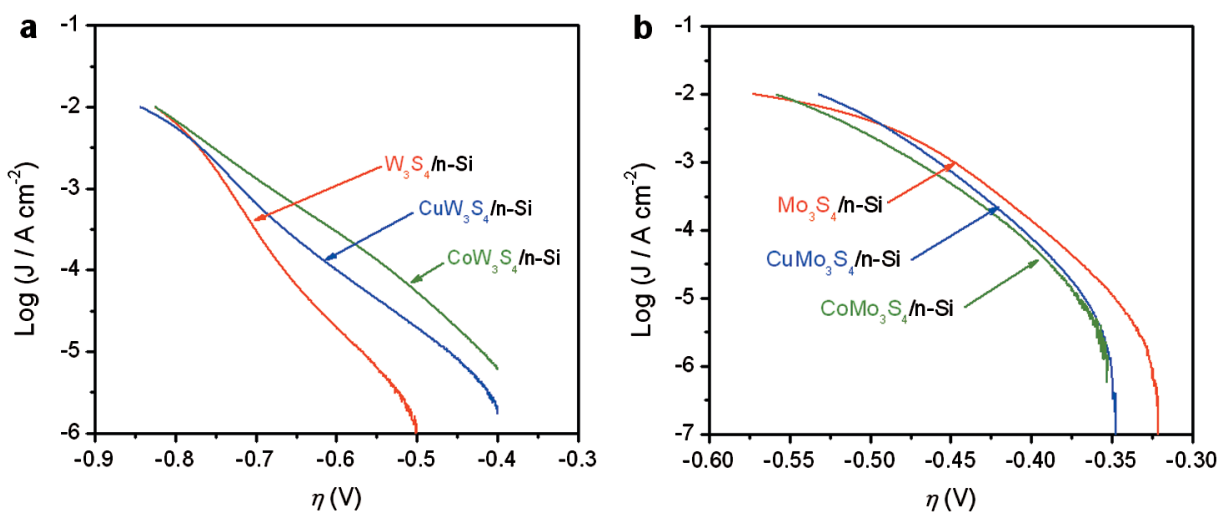

Fig. 9 Tafel polarization curves for the $n$-Si electrodes decorated with (a) W-based clusters and (b) Mo-based clusters in the dark.

The (dark) current density-voltage curves of cluster-decorated $n$-Si are shown in Fig. 8. The overpotentials of hydrogen evolution at a current density of $8 \mathrm{~mA} / \mathrm{cm}^{2}$ are about $-0.8 \mathrm{~V}$ and $-0.5 \mathrm{~V}$ for W-based clusters and Mo-based clusters, respectively. At a current density of $8 \mathrm{~mA} / \mathrm{cm}^{2}$, the potential difference between cluster $/ n-\mathrm{Si}$ in the dark (Fig. 8) and cluster/ $p$-Si under illumination (Fig. 4) is about $0.55 \mathrm{~V}$ in all cases (except for the $\mathrm{CoMo}_{3} \mathrm{~S}_{4} / p$-Si system, which is unstable under illumination [Fig. 4(b)]). This is consistent with the photovoltage expected of the single crystal silicon used in this study ${ }^{29}$ and suggests that one may determine how well a candidate co-catalyst will work for $p$-silicon photocathodes by measuring the HER performance with $n$-Si as a substrate instead. To further understand the HER mechanism of cluster-supported $n$-Si, the Tafel polarization curves are plotted in Fig. 9. The values of the Tafel slope derived from the curves are summarized in Table 1. Tafel slope values for W-based clusters are between 97 and $136 \mathrm{mV} /$ decade. According to the typical relation between the Tafel slope and the corresponding rate-determining step for hydrogen evolution, ${ }^{30}$ it appears that the Volmer reaction acts as the rate-determining step controlling the HER kinetics on W-based clusters at low overpotential. For the Mo-based clusters, the Tafel slope is about $55 \mathrm{mV} /$ decade. This is similar to what has been observed on $\mathrm{MoS}_{2}$ or $\mathrm{MoS}_{\mathrm{x}}$-based materials, ${ }^{31-33}$ indicating that the rate-determining step is either the Heyrovsky reaction or the Tafel reaction. Clearly, there is a significant difference in HER mechanism between the Mo-based clusters and the W-based clusters.

\subsection{DFT Calculations}

To assist in the interpretation of the experimental results, DFT calculations have been used to evaluate the stability of anchored clusters as well as their composition and catalytic properties

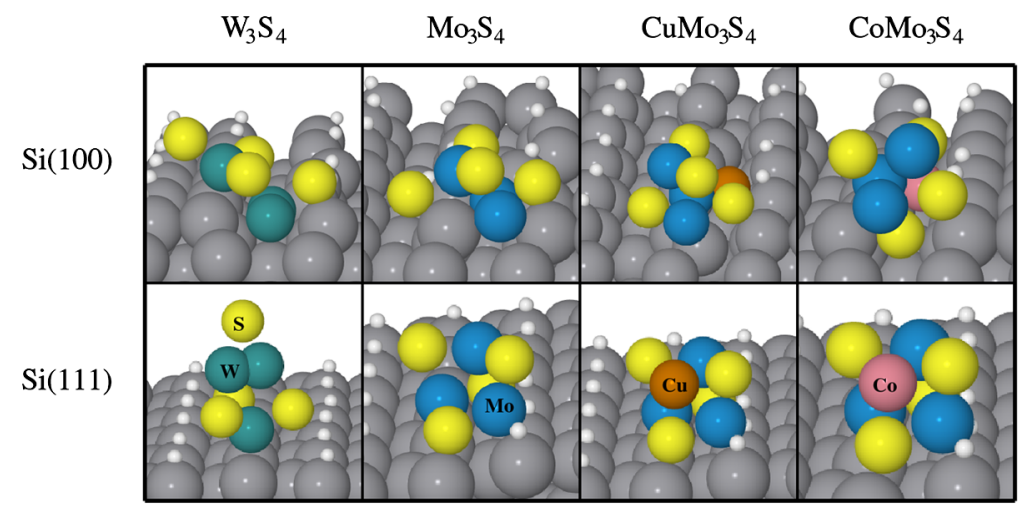

Fig. 10 Geometry of $\mathrm{W}_{3} \mathrm{~S}_{4}, \mathrm{Mo}_{3} \mathrm{~S}_{4}, \mathrm{CuMo}_{3} \mathrm{~S}_{4}$, and $\mathrm{CoMo}_{3} \mathrm{~S}_{4}$ clusters adsorbed on H-passivated $\mathrm{Si}(100)$ and $\mathrm{Si}(111)$. 
under typical electrochemical conditions. The DFT results are summarized in Table 1 alongside the measured electrocatalytic data. The geometries of the anchored clusters, as predicted by DFT, are reported in Fig. 10.

In order to obtain an estimate of the stability of the clusters, or rather of their adhesion to the surface, we first calculated the adsorption energies $\left(E_{\text {ads }}\right)$ for W- and Mo-based clusters on $\mathrm{H}$-terminated $\mathrm{Si}(100)$ and $\mathrm{Si}(111)$. The calculations reveal a pronounced facet effect; in general, but not always, the clusters bind on the order $3 \mathrm{eV}$ stronger (per cluster) to the more open (100) facet than to the (111) facet. They further suggest that the adhesion varies considerably between clusters of different composition; $\mathrm{Mo}_{3} \mathrm{~S}_{4}$ and $\mathrm{CuMo}_{3} \mathrm{~S}_{4}$ are most stable and exhibit similar binding energies, $\mathrm{W}_{3} \mathrm{~S}_{4}$ binds 1.5 to $2 \mathrm{eV}$ weaker, and finally, $\mathrm{CoMo}_{3} \mathrm{~S}_{4}$ binds about $3.5 \mathrm{eV}$ weaker on $\mathrm{Si}(100)$ and more than $1 \mathrm{eV}$ weaker on $\mathrm{Si}(111)$. The comparably weak adsorption of $\mathrm{CoMo}_{3} \mathrm{~S}_{4}$ might explain the rapid loss in activity observed for this system upon repeated cycling of the potential.

The questions about the composition of the clusters and their catalytic activity toward hydrogen evolution have been addressed by studying hydrogen, oxygen, and hydroxyl adsorption on anchored clusters. The binding energies of these species have been defined as the reaction free energies $-\Delta G_{\mathrm{H}^{*}}, \Delta G_{\mathrm{O}^{*}}$ and $\Delta G_{\mathrm{OH}^{*}}(*$ denotes a free site on the cluster where the adsorbate can be attached)—of the reactions:

$$
\begin{gathered}
\mathrm{H}^{+}(\mathrm{aq})+\mathrm{e}^{-}+* \rightarrow \mathrm{H}^{*} \\
\mathrm{H}_{2} \mathrm{O}(\mathrm{aq})+* \rightarrow \mathrm{O}^{*}+2\left(\mathrm{H}^{+}(\mathrm{aq})+\mathrm{e}^{-}\right) \\
\mathrm{H}_{2} \mathrm{O}(\mathrm{aq})+* \rightarrow \mathrm{OH}^{*}+\left(\mathrm{H}^{+}(\mathrm{aq})+\mathrm{e}^{-}\right)
\end{gathered}
$$

The reaction free energies reported in Table 1 have been evaluated assuming standard conditions and a potential $U=0 \mathrm{~V}$ relative to the standard hydrogen electrode (SHE). These conditions imply equilibrium between $\mathrm{H}^{+}(\mathrm{aq})+\mathrm{e}^{-}$and $1 / 2 \mathrm{H}_{2}(\mathrm{~g})$, which allows the use of gas-phase molecular $\mathrm{H}_{2}$ as a reference energy for the $\mathrm{H}^{*}, \mathrm{O}^{*}$, and $\mathrm{OH}^{*}$ binding in Reactions 1 to 3. Moreover, gas-phase $\mathrm{H}_{2} \mathrm{O}$ has been used as reference state in reactions 2 and 3. However, the entropy for $\mathrm{H}_{2} \mathrm{O}$ has been calculated at $0.035 \mathrm{bar}$, the equilibrium pressure of $\mathrm{H}_{2} \mathrm{O}$ at $300 \mathrm{~K}$. The free energy of this reference state is therefore equal to that of liquid water. ${ }^{34}$ When a finite bias voltage $U$ is applied, the energy of the electron will be shifted $-\mathrm{e} U$, thus changing $\Delta G_{\mathrm{H}^{*}}$ with $\mathrm{e} U$, $\Delta G_{\mathrm{O}^{*}}$ with $-2 \mathrm{e} U$, and $\Delta G_{\mathrm{OH}^{*}}$ with $-\mathrm{e} U$. This means, for example, that at $\mathrm{U}=-0.5 \mathrm{~V}$ adsorbed atomic hydrogen is stabilized by $0.5 \mathrm{eV}$ while an adsorbed oxygen is destabilized by $1.0 \mathrm{eV}$ with respect to the values shown in Table 1 .

By analyzing the tabulated reaction energies and comparing them with the corresponding cluster adsorption energies, it is possible to gain some useful insight into the catalytic behavior of the clusters. First, we notice that the underlying substrate plays a decisive role for the reactivity of the clusters. Perhaps not too surprisingly, a strong attractive interaction between the cluster and the substrate reduces the reactivity. Hence, there is a clear tendency for the clusters to lose reactivity as they are moved from the (111) to the (100) facet. Next, the positive $\Delta G_{\mathrm{O}^{*}}$ and $\Delta G_{\mathrm{OH}^{*}}$ found for $\mathrm{W}_{3} \mathrm{~S}_{4}$ on both facets and for $\mathrm{Mo}_{3} \mathrm{~S}_{4}$ on $\mathrm{Si}(100)$ indicate that these clustersubstrate systems are unlikely to dissociate water at potentials cathodic of the SHE, and the clusters will therefore remain unoxidized under experimentally relevant conditions. On these incomplete, unoxidized cubane clusters the free energies of hydrogen adsorption, tabulated in the $\Delta G_{\mathrm{H}^{*}}$ column, are: $0.82 \mathrm{eV}$ on $\mathrm{W}_{3} \mathrm{~S}_{4}$ at $\mathrm{Si}(100), 0.44 \mathrm{eV}$ on $\mathrm{Mo}_{3} \mathrm{~S}_{4}$ at $\mathrm{Si}(100)$, and $0.20 \mathrm{eV}$ on $\mathrm{W}_{3} \mathrm{~S}_{4}$ at $\mathrm{Si}(111)$. These adsorption energies correspond to overpotentials for hydrogen evolution of $-0.82 \mathrm{~V},-0.44 \mathrm{~V}$, and $-0.20 \mathrm{~V}$, respectively. The first two values are in good agreement with the measured overpotentials. For $\mathrm{W}_{3} \mathrm{~S}_{4} / \mathrm{Si}(111)$ the agreement is less favorable, which is thought to be related to poor stability of $\mathrm{W}_{3} \mathrm{~S}_{4}$ on $\mathrm{Si}(111)$ - an issue to which we will return later.

The $\mathrm{Mo}_{3} \mathrm{~S}_{4}$ at $\mathrm{Si}(111)$ system behaves quite differently. In this case, both reaction 2 and reaction 3 are exothermic at SHE. Noticeably, the adsorption of $\mathrm{OH}$ is so strong that $\mathrm{OH}$ is expected to remain attached to $\mathrm{Mo}_{3} \mathrm{~S}_{4}$ down to well below $U=-0.5 \mathrm{~V}$ vs. SHE. As a result, $\mathrm{Mo}_{3} \mathrm{~S}_{4} \mathrm{OH}$ instead of $\mathrm{Mo}_{3} \mathrm{~S}_{4}$ is the cluster to be considered in the hydrogen evolution regime. 
$\Delta G_{\mathrm{H}^{*}}$ for $\mathrm{Mo}_{3} \mathrm{~S}_{4} \mathrm{OH}$ anchored on $\mathrm{Si}(111)$ is $0.29 \mathrm{eV}$. This free energy corresponds to a theoretical overpotential of $-0.29 \mathrm{~V}$, which is also rather consistent with the overpotential measured for $\mathrm{Mo}_{3} \mathrm{~S}_{4}$. Likewise, $\mathrm{O}$ and $\mathrm{OH}$ adsorb exothermically on both $\mathrm{CuMo}_{3} \mathrm{~S}_{4}$ and $\mathrm{CoMo}_{3} \mathrm{~S}_{4}$ at SHE, and again $\mathrm{OH}$ is the most stable of the two adsorbates at almost all negative potentials. The calculated $\Delta G_{\mathrm{H}}$ 's for $\mathrm{CuMo}_{3} \mathrm{~S}_{4} \mathrm{OH}$ and $\mathrm{CoMo}_{3} \mathrm{~S}_{4} \mathrm{OH}$ vary between 0.16 and $0.46 \mathrm{eV}$-that is, they span basically the same range of energies as those obtained for $\mathrm{Mo}_{3} \mathrm{~S}_{4}$ and $\mathrm{Mo}_{3} \mathrm{~S}_{4} \mathrm{OH}$. This could help explain for the similar electrocatalytic activity observed for all Mo-based clusters. In connection with the discussions described above, it is also worth noticing that adsorption of $\mathrm{OH}$ (and $\mathrm{O}$ ) changes the oxidation state of the cluster, which in turn might dramatically change the hydrogen adsorption free energy. For example, when $\mathrm{OH}$ is being attached to $\mathrm{CuMo}_{3} \mathrm{~S}_{4}$ anchored on $\mathrm{Si}(111), \Delta G_{\mathrm{H}^{*}}$ increases from $-0.42 \mathrm{eV}$ to $0.34 \mathrm{eV}$.

As a final comment on the computational results, we would like to expand on the aforementioned seeming disagreement between calculated and measured overpotentials for $\mathrm{W}_{3} \mathrm{~S}_{4}$ / $\mathrm{Si}(111)$. The calculations predict an overpotential of $-0.20 \mathrm{~V}$, whereas the measured overpotential is of the order -0.7 or $-0.8 \mathrm{~V}$ (Fig. 8). Though the reason for the discrepancy is still unclear, one could think of at least two plausible explanations. First, since the interaction between $\mathrm{W}_{3} \mathrm{~S}_{4}$ and $\mathrm{H}$-passivated $\mathrm{Si}(111)$ is relatively weak, it is possible that these clusters will quickly desorb from the $\mathrm{Si}$ surface and thus only clusters attached to $\mathrm{Si}(100)$ or to lowcoordinated defect sites will contribute to the measured cyclic voltammograms. That could resolve the issue, as we have already seen that the overpotential calculated for $\mathrm{W}_{3} \mathrm{~S}_{4} / \mathrm{Si}(111)$ matches the experimental value. A second possibility is that the adsorption configuration found for $\mathrm{W}_{3} \mathrm{~S}_{4}$ at $\mathrm{Si}(111)$ is not the (true) global minimum-energy configuration, but perhaps a local minimum instead; the somewhat odd adsorption geometry obtained for the $\mathrm{W}_{3} \mathrm{~S}_{4}$ cluster (see Fig. 10) lends some credibility to this hypothesis. According to what we have seen for the other clusters, we would expect a stabilization of the cluster to result in a reduction of its reactivity, which would bring the theoretical overpotential closer to the experimental counterpart.

\subsection{Perspective}

It is hard to directly compare the HER performance of the cubane clusters (on $\mathrm{Si}$ ) with those previously found for nanoparticulate $\mathrm{MoS}_{2}$ and $\mathrm{WS}_{2}$ with or without co-doping (on other support materials like gold, HOPG, and other forms of carbon, FTO, etc.). The nanoparticulate catalysts supported on gold or carbon supports have shown promise, ${ }^{10,31}$ and recently, amorphous $\mathrm{MoS}_{x}$ has shown impressive performance on FTO support ${ }^{32}$ and highly active $\mathrm{MoS}_{2}$ has been grown on $\mathrm{MoO}_{3}$ nanowires ${ }^{33}$ and on reduced graphene oxide, ${ }^{35}$ but none of these materials has yet been successfully interfaced with silicon. Making the assumption that $n$-Si in the dark is analogous to these ohmic supports, it seems that the onset potential for HER on the Mobased clusters ( $\sim-0.4 \mathrm{~V}$ vs. RHE) is roughly $0.2 \mathrm{~V}$ more negative than that of nanoparticulate $\mathrm{MoS}_{2}$. Another notable difference is that while nanoparticulate $\mathrm{WS}_{2}$ has about the same overpotential as $\mathrm{MoS}_{2}$, the W-based cubane clusters have far higher overpotential than Mo-based clusters (HER onset is about $-0.65 \mathrm{~V}$ vs. RHE).

If the band bending of the $p$-Si could be increased (e.g., by shallow $n^{+}$-doping near the surface as recently shown by Boettcher et $\mathrm{al}^{36}$ ), then a better catalyst than the present champion $\mathrm{Mo}_{3} \mathrm{~S}_{4}$-cluster would be needed. Given that it has not been confirmed that $\mathrm{MoS}_{2}$-type structures can be grown and be stable on the Si-surface, cubane clusters such as $\mathrm{CrMo}_{3} \mathrm{~S}_{4}$ or $\mathrm{WMo}_{3} \mathrm{~S}_{4}$ look appealing. The present work demonstrates the importance of considering the adsorption of $\mathrm{H}$, $\mathrm{OH}$, and $\mathrm{O}$ on the catalytic clusters, and this may broaden the perspective for finding more optimal catalysts.

\section{Conclusions}

We have measured electrochemical and photoecletrochemical behaviors of Si pyramids decorated with a series of cubane-like clusters in detail. The influence of the cluster-core unit on the photoevolution of hydrogen on $p$-Si is shown to follow the trend of the dark evolution of hydrogen over $n$-Si. When a $p$-Si electrode is decorated with Mo-based clusters, it catalyzes hydrogen photoevolution at potentials up to $0.6 \mathrm{~V}$ more positive than those of the bare $p$-Si electrode. 
Hou et al.: Photoelectrocatalysis and electrocatalysis on silicon electrodes...

Mo-based clusters generally exhibit lower overpotential than the W-based ones by about $0.3 \mathrm{~V}$. DFT calculations corroborate the experimental electrochemical characteristics of the clusters supported on the silicon surface by, for example, predicting the low activity and low stability of $\mathrm{CoMo}_{3} \mathrm{~S}_{4}$. Although it should be pointed out that none of the new clusters investigated here constitute an improvement in activity over the previously reported $\mathrm{Mo}_{3} \mathrm{~S}_{4}$-cluster, the greatly expanded library of HER activity data will help direct future studies-for example, to focus on Mo-based clusters rather than W-based clusters.

\section{Acknowledgments}

This work was performed as part of the Catalysis for Sustainable Energy initiative, which is funded by the Danish Ministry of Science, Technology, and Innovation. This material is also based upon work funded by Inner Nordic Energy Research Program 09-064270 and the U.S. Dept. of Energy, Office of Basic Energy Science. The Center for Individual Nanoparticle Functionality is funded by the Danish National Research Foundation, while the Center for Atomic-scale Materials Design is funded by the Lundbeck Foundation. P.C.K Vesborg is funded by the Danish Council for Independent Research-FTP (Project number: 10-080861).

\section{References}

1. N. S. Lewis and D. G. Nocera, "Powering the planet: chemical challenges in solar energy utilization," Proc. Natl. Acad. Sci. USA 103(43), 15729-15735 (2006).

2. M. F. Weber and M. J. Dignam, "Efficiency of splitting water with semiconducting photoelectrodes,” J. Electrochem. Soc. 131(6), 1258-1265 (1984), http://dx.doi.org/10.1149/1.2115797.

3. M. F. Weber and M. J. Dignam, "Splitting water with semiconducting photoelectrodesefficiency considerations," Int. J. Hydrogen Energy 11(4), 225-232 (1986), http://dx.doi .org/10.1016/0360-3199(86)90183-7.

4. O. Khaselev and J. A. A. Turner, "A monolithic photovoltaic-photoelectrochemical device for hydrogen production via water splitting," Science 280(5362), 425-427 (1998), http://dx .doi.org/10.1126/science.280.5362.425.

5. M. G. Walter et al., "Solar water splitting cells," Chem. Rev. 110(11), 6446-6473 (2010), http://dx.doi.org/10.1021/cr1002326.

6. R. N. Dominey et al., "Improvement of photoelectrochemical hydrogen generation by surface modification of $p$-type silicon semiconductor photocathodes," J. Am. Chem. Soc. 104(2), 467-482 (1982), http://dx.doi.org/10.1021/ja00366a016.

7. J. O'M. Szklarczyk and M. Bockris, "Photoelectrocatalysis and electrocatalysis on p-Silicon," J. Phys. Chem. 88(9), 1808-1815 (1984).

8. J. K. Nørskov et al., "Trends in the exchange current for hydrogen evolution," J. Electrochem. Soc. 152(3), J23-26 (2005), http://dx.doi.org/10.1149/1.1856988.

9. B. Hinnemann et al., "Biomimetic hydrogen evolution: $\mathrm{MoS}_{2}$ nanoparticles as catalyst for hydrogen evolution," J. Am. Chem. Soc. 127(15), 5308-5309 (2005).

10. J. Bonde et al., "Hydrogen evolution on nano-particulate transition metal sulfides," Faraday Discuss. 140, 219-231 (2009).

11. T. F. Jaramillo et al., "Hydrogen evolution on supported incomplete cubane-type $\left[\mathrm{Mo}_{3} \mathrm{~S}_{4}\right]^{4+}$ electrocatalysts," J. Phys. Chem. C 112(45), 17492-17498 (2008), http://dx.doi.org/10 .1021/jp802695e.

12. Y. Hou et al., "Bioinspired co-catalysts bonded to a silicon photocathode for solar hydrogen evolution," Nat. Mater. 10(6), 434-438 (2011), http://dx.doi.org/10.1038/nmat3008.

13. M. N. Sokolov, V. P. Fedin, and A. G. Sykes, "Chalcogenide-containing metal clusters," Chapter 4.12 in Comprehensive Coordination Chemistry II: From Biology to Nanotechnology, J. A.McCleverty and T. J. Meyer, Eds., Vol. 4, pp. 761-823, Elsevier, Amsterdam (2004).

14. R. Llusar and S. Uriel, "Heterodimetallic chalcogen-bridged cubane-type clusters of molybdenum and tungsten containing first-row transition metals," Eur. J. Inorg. Chem. (7), 1271-1290 (2003).

15. K. Herbst et al., "Heterobimetallic cubane-like cluster compounds prepared as the homologous series $\left[\left(\eta^{5}-\mathrm{Cp}^{\prime}\right)_{3} \mathrm{Mo}_{3} \mathrm{~S}_{4} \mathrm{M}^{\prime}\left(\mathrm{PPh}_{3}\right)\right]^{+}\left(\mathrm{M}^{\prime}=\mathrm{Ni}, \mathrm{Pd}, \mathrm{Pt}\right)$. Crystal structures show 
that platinum is smaller than palladium," Organometallics 20(17), 3655-3660 (2001), http://dx.doi.org/10.1021/om010151q.

16. K. Herbst, L. Dahlenburg, and M. Brorson, "Methylcyclopentadienyl-substituted tungsten(IV) sulfide cluster $\left[\left(\eta^{5}-\mathrm{Cp}^{\prime}\right)_{3} \mathrm{~W}_{3} \mathrm{~S}_{4}\right]^{+}$and its heterobimetallic derivative $\left[\left(\eta^{5}-\mathrm{Cp}^{\prime}\right)_{3} \mathrm{~W}_{3} \mathrm{~S}_{4} \mathrm{Ni}\left(\mathrm{PPh}_{3}\right)\right]^{+}$, " Inorg. Chem. 40, 1989-1992 (2001).

17. K. Herbst and L. Dahlenburg, "Tris[1,2,3( $\left.\eta^{5}\right)$-methylcyclopentadienyl]- $\mu_{3}$-sulfido-tri- $\mu_{2}$ sulfido-tritungsten $p$-toluenesulfonate," Acta Cryst. E 63(4), m1099-m1100 (2007), http://dx.doi.org/10.1107/S1600536807011762.

18. K. Herbst, M. Monari, and M. Brorson, "Facile formation of a heterobimetallic cluster with a cubane-like $\left[\mathrm{Mo}_{3} \mathrm{~S}_{4} \mathrm{Cu}\right]^{5+}$ core," Inorg. Chim. Acta 357(3), 895-899 (2004), http://dx.doi .org/10.1016/S0020-1693(03)00497-3.

19. K. Herbst, L. Dahlenburg, and M. Brorson, "Synthesis of the new, cubane-like $\mathrm{W}_{3} \mathrm{~S}_{4} \mathrm{Co}$ cluster core. Completion of the homologous series $\left[\left(\eta^{5}-\mathrm{Cp}^{\prime}\right)_{3} \mathrm{Mo}_{3} \mathrm{~S}_{4} \mathrm{Co}(\mathrm{CO})\right]$ $(\mathrm{M}=\mathrm{Cr}$, Mo, W)," Inorg. Chem. 43(11), 3327-3328 (2004), http://dx.doi.org/10.1021/ ic049742+.

20. K. Herbst et al., "Variation of the electron population by four units in the cluster series $\left[\left(\eta^{5}-\mathrm{Cp}^{\prime}\right)_{3} \mathrm{Mo}_{3} \mathrm{~S}_{4} \mathrm{Co}(\mathrm{L})\right]^{\mathrm{n}+}\left(\mathrm{L}=\mathrm{I}, \mathrm{CO}, \mathrm{PPh}_{3}, \mathrm{NO} ; n=0,1\right)$, Inorg. Chim. Acta 360(8), 2697-2703 (2007), http://dx.doi.org/10.1016/j.ica.2007.01.014.

21. Y. Hou et al., "Bio-inspired co-catalysts bonded to a silicon photocathode for solar hydrogen evolution," Proc. SPIE Int. Soc. Opt. Eng. 8109, 81090Q-1-81090Q-8 (2011)

22. E. Vazsonyi et al., "Improved anisotropic etching process for industrial texturing of silicon solar cells," Sol. Energy Mater. Sol. Cells 57(2), 179-188 (1999), http://dx.doi.org/10.1016/ S0927-0248(98)00180-9.

23. M. C. Payne et al., "Iterative minimization techniques for ab initio total-energy calculations: molecular dynamics and conjugate gradients," Rev. Mod. Phys. 64(4), 1045-1097 (1992), http://dx.doi.org/10.1103/RevModPhys.64.1045.

24. G. Kresse and J. Furthmüller, "Efficiency of ab initio total-energy calculations for metals and semiconductors using a plane-wave basis set," Comp. Mater. Sci. 6(1), 15-50 (1996), http://dx.doi.org/10.1016/0927-0256(96)00008-0.

25. Dacapo pseudopotential code, URL: https://wiki.fysik.dtu.dk/dacapo, Center for Atomicscale Materials Design (CAMD), Technical University of Denmark, Lyngby (2009).

26. B. Hammer, L. B. Hansen, and J. K. Nørskov, "Improved adsorption energetics within density-functional theory using revised Perdew-Burke-Ernzerhof functionals," Phys. Rev. B 59(11), 7413-7421 (1999), http://dx.doi.org/10.1103/PhysRevB.59.7413.

27. D. Vanderbilt, "Soft self-consistent pseudopotentials in a generalized eigenvalue formalism," Phys. Rev. B 41(11), 7892-7895 (1990), http://dx.doi.org/10.1103/PhysRevB.41.7892.

28. L. Bengtsson, "Dipole correction for surface supercell calculations," Phys. Rev. B 59(19), 12301-12304 (1999), http://dx.doi.org/10.1103/PhysRevB.59.12301.

29. S. W. Boettcher et al., "Energy-conversion properties of vapor-liquid-solid grown silicon wire-array photocathodes," Science 327(5962), 185-187 (2010), http://dx.doi.org/10.1126/ science.1180783.

30. B. E. Conway and B. V. Tilak, "Interfacial processes involving electrocatalytic evolution and oxidation of $\mathrm{H}_{2}$, and the role of chemisorbed H," Electrochim. Acta 47(22-23), 35713594 (2002), http://dx.doi.org/10.1016/S0013-4686(02)00329-8.

31. T. F. Jaramillo et al., "Identification of active edge sites for electrochemical $\mathrm{H} 2$ evolution from $\mathrm{MoS}_{2}$ nanocatalysts," Science 317(5834), 100-102 (2007), http://dx.doi.org/10.1126/ science.1141483.

32. D. Merki et al., "Amorphous molybdenum sulfide films as catalysts for electrochemical hydrogen production in water," Chem. Sci. 2(7), 1262-1267 (2011).

33. Z. Chen et al., "Core-shell $\mathrm{MoO}_{3}-\mathrm{MoS}_{2}$ nanowires for hydrogen evolution: a functional design for electrocatalytic materials," Nano Lett. 11(10), 4168-4175 (2011).

34. P. W.Atkins, Physical Chemistry, fourth ed., p. 943, Oxford University Press, Oxford (1992).

35. Y. Li et al., " $\mathrm{MoS}_{2}$ nanoparticles grown on graphene: an advanced catalyst for the hydrogen evolution reaction," J. Am. Chem. Soc. 133(19), 7296-7299 (2011).

36. S. W. Boettcher et al., "Photoelectrochemical hydrogen evolution using Si microwire arrays," J. Am. Chem. Soc. 133(5), 1216-1219 (2011). 


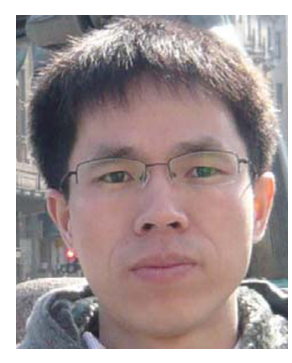

Yidong Hou obtained his B.S. in chemistry (2004) and Ph.D. in industrial catalysis (2007) from Fuzhou University, China. Following postdoctoral work with Ib Chorkendorff at Technical University of Denmark (20082011), he returned to Fuzhou University to join the faculty as an assistant professor. His research interests include semiconductor photocatalysis for use in solar-energy conversion and environmental remediation.

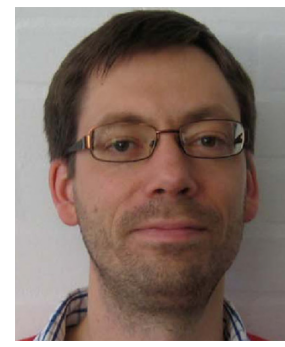

Mårten E. Björketun received his M.Sc. in applied physics and electrical engineering from Linköping Institute of Technology (2000) and obtained his Ph.D. in physics at the Department of Applied Physics, Chalmers University of Technology (2007), under the supervision of Prof. Göran Wahnström. His thesis research, which was based on density functional theory calculations, focused on the defect chemistry and proton transport properties of solid oxides. Since 2007 he has been a Post-doctoral Research Associate and later Research Associate at the Center for Atomic-scale Materials Design (CAMD), Department of Physics, Technical University of Denmark. His current research interests include theoretical descriptions of electrochemical interfaces and charge transfer reactions, electrochemical $\mathrm{CO} 2$ reduction, and electrochemical and photoelectrochemical hydrogen production.

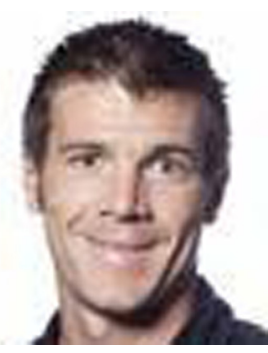

Brian Segeris currently is postdoctoral researcher at DTU. Previously he worked as a postdoctoral researcher under Lianzhou Wang at the University of Queensland (Australia). His PhD was done under the guidance of Prashant Kamat at the University of Notre Dame where he focused on nanostructured electrochemical systems in relation to fuel cells and photoelectrochemical cells. His research interests include photoelectrochemical water splitting, photoelectrochemical organic degradation, and carbon based supports, such as graphene and carbon nanotubes.

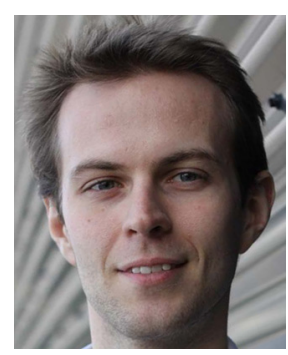

Thomas Pedersen received the Ph.D. degree in 2010 from Technical University of Denmark, Department of Micro and Nanotechnology. He has previously been working with development and fabrication of capacitive pressure sensors and piezoelectric micromachined ultrasound transducers. He is now employed as a post doc at DTU Nanotech and is currently working with design and fabrication of micro reactors for study of catalytic reactions and photocatalysis.

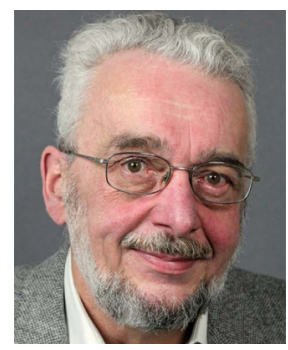

Ole Hansen is Associate Professor at DTU Nanotech, the Technical University of Denmark, where he is heading the Silicon Microtechnology group, with activities within lithography based micro- and nano-technology. He received his MSc degree within micro-technology from Technical University of Denmark in 1977, and has since then worked with micro- and nano-technology and applications of the technology within electronics, metrology, sensing, catalysis and energy harvesting. Current research interests include photo-catalysis and tools for characterizing catalytic processes. Since 2005 he has been part of the Danish National Research Foundation Center CINF, Center for Individual Nanoparticle Functionality. 


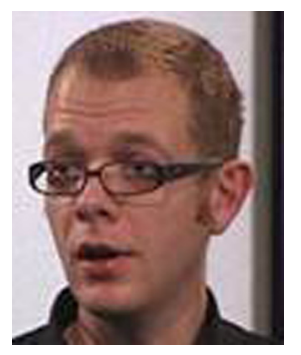

Jan Rossmeisl is since 2009 Associated Professor at Department of Physics at the Technical University of Denmark (DTU). He is heading the Theoretical Electrochemistry Group, part of the Center for Atomic scale Materials Design. Rossmeisl received a Ph.D. in solid state physics from DTU in 2004. He is the author or co-author of around 60 peerreviewed scientific articles and has mentored approximately 18 postdoctoral fellows and graduate students. His research interests include: Density functional theory simulations, Photo and electro-catalysis for energy conversion, modeling of charged interfaces and charge transfer reactions, material design of catalysis of the oxygen reduction/evolution and hydrogen evolution/oxidation reactions.

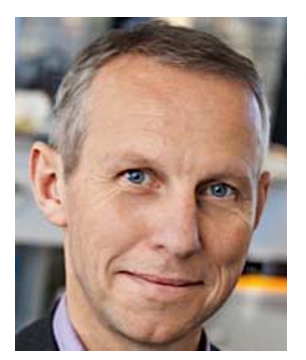

Søren Dahl is Professor at the Technical University of Denmark, where he also received his $\mathrm{PhD}$ in surface science studies of ammonia synthesis in 1999. He then worked for 10 years in industrial R\&D at the catalysts company Haldor Topsøe. In 2009 he became a professor at the Technical University of Denmark in connection with the research initiative "Catalysis for Sustainable Energy". His current research interests are associated with design of catalysts for energy conversion based on fundamental

understanding.

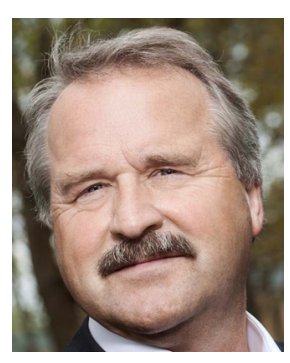

Ib Chorkendorff got his $\mathrm{PhD}$ in 1985 in experimental surface science from Odense University, Denmark. After working as a post-doc with Prof. John T. Yates Jr. at University of Pittsburgh, USA, he was employed in 1987 at DTU to establish an experimental activity within surface physics, investigating fundamental aspects of heterogeneous catalysis. In 2005 he established the Center for Individual Nanoparticle Functionality (CINF), and broadened these activities to include technologies for producing solar fuels utilizing electro- and photo-catalysis, for finding new and effective materials for improving sustainable energy conversion and environmental protection.

Biographies and photographs of other authors not available. 